\title{
Analysis of seismic response and economic performance of CS wallboard high-rise buildings

\author{
Ji Jingzhe ${ }^{1}$, Zhang Mingjie ${ }^{2}$ and Li Zhiguo ${ }^{3}$
} \\ ${ }^{1}$ Central-South Architectural Design Institute Co. Ltd, Wuhan 430071 ,China \\ ${ }^{2}$ China United Engineering Corporation Ltd, Hangzhou 310022, China \\ ${ }^{3}$ Department of Civil Engineering, Tianjin University, Tianjin 300072 ,China. \\ ${ }^{a}$ Corresponding author: zhangmingjie0823@126.com
}

\section{Keywords:seismic response, economic performance,CS wallboard, high-rise buildings}

Abstract. In order to ameliorate the poor durability and fireproof performance of high-rise building external thermal insulation, CS wallboard is applied to high-rise buildings .Using response spectrum method and time-history analysis method, the high-rise buildings with this composite wallboard as the main bearing member is analyzed. And dynamic characteristics of structure of this composite wallboard and shear wall of reinforced concrete are compared. The calculation results show that the structure has enough stiffness and lateral displacement capacity, and the material is saved $13 \%$.

The plate made of wire gauze with polystyrene, also known as CS plate, which is a new type thermal insulation composite wallboard, using low carbon cold drawing of galvanized steel wire welded space grid structure filled with flame retardant polystyrene board or rock wool board, on both sides laying fine stone concrete or cement mortar. CS plate has the advantages of light, heat preservation, saving energy and flexibility, and its structure is shown as Figure 1
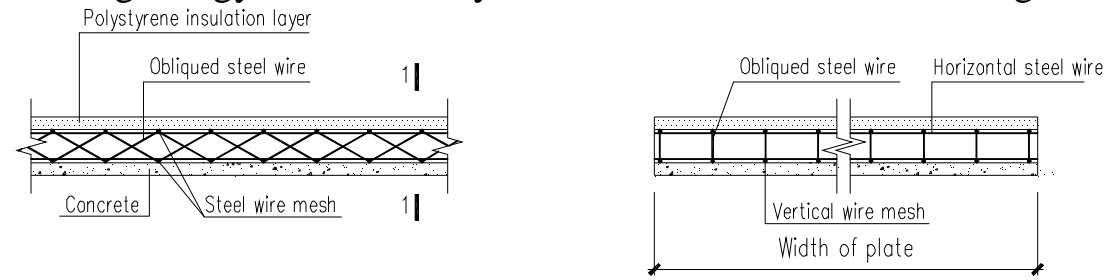

FIGURE 1. CS plate section construction.

\section{REQUIREMENTS ON FIRE PROTECTION AND DURABILITY OF BUILDING WALLS}

China has made clear provisions on building energy saving since 1986, formulated three steps to save energy from 35 to 50 percent to 65 percent, The third energy conservation goal is now being rolled out in major cities, which is to save 65 percent on the typical residential heating energy consumption in the early 1980s. Therefore, the buildings have insulation layer in the outer wall to meet the corresponding energy-saving requirements. However, in the project, the thin plaster exterior insulation system using organic materials is widely used (EPS XXPS and so on), and its durability is far from the service life of the construction subject. The insulation layer is difficult to maintain and replace, and The loss of insulation material also poses a serious safety hazard to the use of buildings ${ }^{[1]}$. The project urgently needs a good durable wall. Year 2009, the ministry of public security, the ministry of housing and urban-rural development jointly issued the "Temporary regulations for exterior insulation system and exterior decoration of civil buildings", which specifies that for buildings with height greater than $100 \mathrm{~m}$, the combustion performance of the insulation materials should be $\mathrm{A}^{[2]}$. The promulgation has raised the fireproof performance of the exterior wall to a new height.

The CS wallboard is a form of insulation for the external wall, which is the composite wall formed by the forming of the concrete and insulation materials in the wall. The wall's insulation thickness can 
be adjusted according to different energy saving requirements, and the form of insulation also improves the fire safety performance of the whole system. The test proved that the fire resistance limit of the load-bearing CS wallboard was above 3 hours, achieved Non-flammable Grade A. This structure of CS wallboard let the insulation layer have the more than $50 \mathrm{~mm}$ thick concrete wall's protection, its' fire protection performance is reliable, and can have the same service life as the main structure of the house, eliminating the hidden danger of the insulation layer's fall off.

\section{SEISMIC RESPONSE ANALYSIS}

\section{Project profile}

This paper is based on a 28-layer shear wall structure of high-rise flats in China TianJin, as shown in figure 2. Design durable years of this project is 50 years, Building's site classification is II, ground roughness is B, and building's storey height is $3 \mathrm{~m}$, shear wall thickness is $200 \mathrm{~mm}$. When the structure is modeled, the main load-bearing component--the ordinary concrete shear wall is replaced by the loadbearing CS wallboard, and the insulation layer of the CS wallboard is $40 \mathrm{~mm}$, and the concrete layer on both sides is $80 \mathrm{~mm}$. This paper analyzes the self-vibration characteristics of this structure's buildings and compares the dynamic response and economic performance with ordinary shear wall structure.

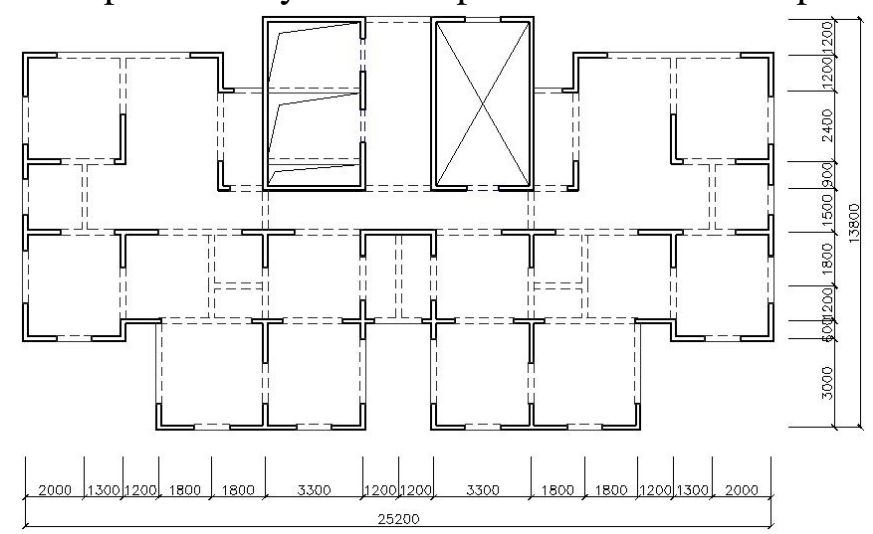

FIGURE 2. Layout plan of structure.

This paper model and finite element analysis by model (PM) and analyze (STAWE) module in general design software PKPM, developed by the China Academy of Building Research (CABR).

\section{Self-vibration characteristics analysis}

The stiffness equivalent model is used in the study of complex composite wall structure. Through the equivalent treatment of stiffness, this method replaces the composite wall with the same length concrete wall, which have the same stiffness. Therefore, the structure in figure 1 shows that the wall thickness of the equivalent of the load-bearing CS wallboard is the sum of the thickness of the concrete on both sides ${ }^{[3]}$. For the structure of shear wall with strong coupling, if the calculation adopts rigid floor assumption, the lateral stiffness of the shear wall has little contribution to the lateral stiffness of the whole structure, so the calculation generally ignored the contribution of the external stiffness of the shear wall. The out of plane stiffness of the load-bearing CS wallboard is greater than the equivalent thickness of the wall's

With the software finite element analysis, the first 15th self-oscillation period of the structure is calculated, the period and translation coefficient is listed in table 1. Calculation results shows that the vibration characteristics of CS wallboard high-rise buildings are similar to the ordinary shear wall highrise buildings. The first two modes are the horizontal vibration mainly in the direction of $\mathrm{X}$ or $\mathrm{Y}$, and the third mode is the torsional vibration with the center of mass as the torsion center. The cycle ratio of the model is 0.60 . The high-rise buildings of CS wallboard can also meet the requirements of 
uniformity and symmetry in the design of ordinary high-rise buildings, and reasonable plane layout will effectively reduce the torsion effect of the structure.

\section{Analysis of mode-superposition response spectrum}

The dynamic characteristics of the structure were analyzed by the mode decomposition response spectrum method, and the calculated structural displacement was shown in FIG. 3. The maximum displacement of each floor is increased uniformly, without sudden increase, the layer's shear bearing capacity of the model is 0.93 and the interval stiffness ratio of the model is 1.02 , both are not exceed the specification limit. It shows that the structure has no obvious weak layer. The minimum shear weight of the floor is $3.01 \%$ ( $\mathrm{X}$ direction) and $2.75 \%$ (Y direction). The ratio of rigidity-to-gravity is 9.11 (X direction) and 6.15 (Y direction), meeting the specification requirements. The maximum interlayer displacement Angle of the structure is 1/1475 (X direction) and 1/1260 (Y direction), which is less than $1 / 1000$ of the displacement limit, indicating that the structure has sufficient stiffness and anti-lateral ability.

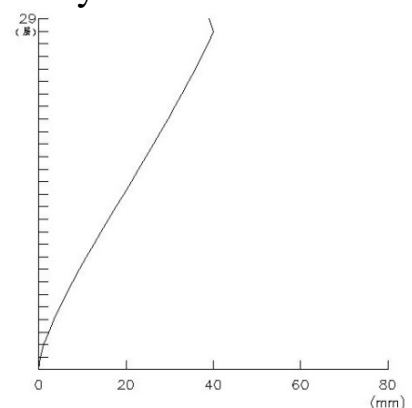

$\mathrm{X}$ direction

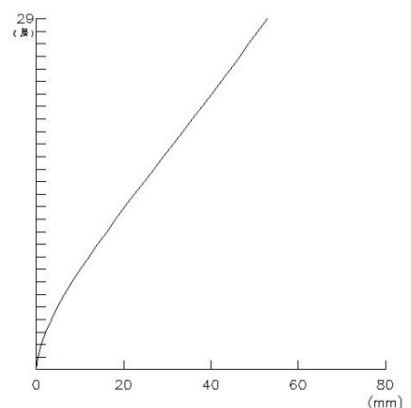

Y direction

FIGURE 3. The calculated structural displacement.

\section{Time -history analysis}

In order to analyze the dynamic characteristics of CS wallboard high-rise buildings with new thermal insulation wall, the structure is complemented calculated by the elastic time-history analysis method. The characteristic period of the structure is $0.40 \mathrm{~s}$, and the maximum value of the earthquake acceleration is $55 \mathrm{~cm} / \mathrm{s} 2$, considering the field type, designing seismic grouping and other factors, two actual seismic records in the SATWE program (TH2TG040, MAMMOTH LAKES AFTERSHOCK 1980.5.25, and TH4TG040, P COALINGA EARTHQUAKE 1983.5.2) and a set of simulated acceleration time curves (RH1TG040) are selected. The actual earthquake record is adjusted by the ratio of the maximum acceleration of Time-history analysis's and the actual earthquake's. The calculated of structure interlayer displacements under earthquake action is shown in FIG. 4.

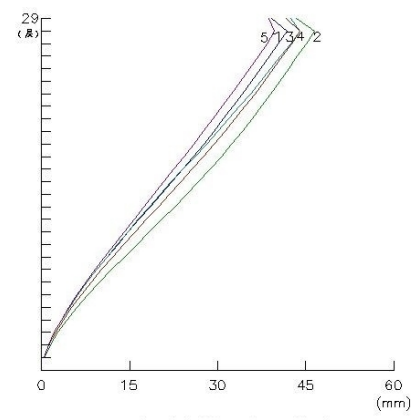

$\mathrm{X}$ direction

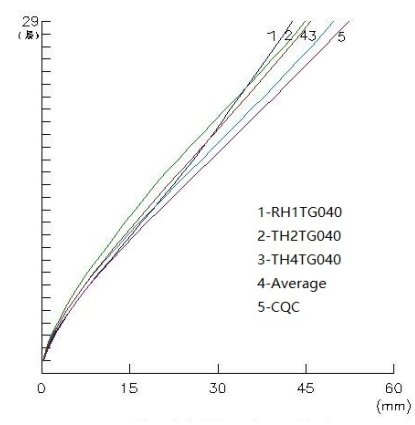

Y direction

FIGURE 4. The calculated interlayer displacement curve.

The results show that the shear force of the structure on time-history analysis is not less than $65 \%$ of the calculated on the vibration-type decomposition reaction spectrum analysis, and the average of base shear on time-history analysis is not less than $80 \%$ of the calculated value of the vibration-type decomposition reaction spectrum. The calculation results meet the requirement of seismic wave 
selection in specification. The maximum interlayer displacement Angle of the calculated model under the action of seismic waves is 1/1384 ( $\mathrm{X}$ direction) and 1/1387 (Y direction), and the displacement limit is less than $1 / 1000$. The difference between the calculated results and the elastic displacement of vibration-type decomposition reaction spectra is also within the reasonable range.

The total thickness of the wall of CS wall is consistent with that of ordinary shear wall, while the CS wallboard has a certain thickness of insulation layer, the stiffness and total mass are much smaller than that of ordinary concrete shear walls. So, the base total shear force of the high-rise building with CS wallboard is much smaller than that of the high-rise building with ordinary concrete shear wall, and the internal force allocated to each wall decreased. Therefore, in the case of meeting interlayer displacement requirements, CS wallboard structure is more favorable to earthquake resistance than normal concrete shear wall structure.

TABLE 1. Total shear at base and Economic performance.

\begin{tabular}{|c|c|c|c|c|}
\hline \multirow[b]{2}{*}{ MODEL } & \multicolumn{2}{|c|}{$\begin{array}{l}\text { Total shear at base } \\
(\mathbf{k N})\end{array}$} & \multirow{2}{*}{$\begin{array}{l}\text { Total mass } \\
\text { (T) } \\
\text { Including the } \\
\text { load }\end{array}$} & \multirow[b]{2}{*}{$\begin{array}{l}\text { Total concrete } \\
\left(\mathbf{m}^{3}\right)\end{array}$} \\
\hline & $\begin{array}{l}\text { X } \\
\text { directio } \\
\text { n }\end{array}$ & $\begin{array}{l}\mathbf{Y} \\
\text { directio } \\
\mathbf{n}\end{array}$ & & \\
\hline CS wall high-rise buildings & 3338.95 & 3047.33 & 11074.806 & 2496.28 \\
\hline $\begin{array}{l}\text { Ordinary concrete shear wall } \\
\text { structure }\end{array}$ & 3701.19 & 3375.61 & 11932.565 & 2860.83 \\
\hline
\end{tabular}

\section{ECONOMIC PERFORMANCE ANALYSIS}

Economic performance is also an important index in architectural engineering design. Under the premise of satisfying the use function, the owner will choose the most economical scheme in each scheme.

The economic comparison of the CS wallboard scheme is carried out, and the calculation results are shown in table 2.According to the calculation results, compared with ordinary concrete shear wall structure, the overall quality of CS wallboard scheme decreased by $7.2 \%$, and the total base shear force decreased by $9.8 \%$ (average). This can reduce the base load, reduce the design requirements for the foundation, and reduce the cost of the base part. In addition, the total amount of concrete used in the project was reduced by $12.7 \%$. In the case that the axial pressure ratio meets the requirement, the high structure of CS wallboard can achieve the good economic benefit of nearly $13 \%$.

\section{CONCLUSION}

According to the vibration mode decomposition response spectrum method and time history analysis method of the calculation results, the indicators of CS wall high-rise buildings are able to meet the requirements of the current specification, CS wall structure has enough stiffness and lateral resistance.

When the high-rise building of CS wallboard meets the displacement between layers, the total stiffness of the structure is reduced, and the seismic response is reduced, and the seismic performance is better than that of ordinary concrete shear wall structure. It also has the advantages of good durability, good fireproof performance, light weight and fast construction speed. It is a kind of building system worth popularizing.

In under the condition of axial compression ratio, $\mathrm{CS}$ wall high-rise buildings to reduce the total mass, reduces the requirement for foundation design, but also can save nearly $13 \%$ of the materials good economic benefits. CS wall has economic performance. 


\section{REFERENCES}

1. LI Yingquan, XU Luoyi, WANG Mingxuan, HU Shikai, DUAN Ce and ZHU Lide, Grade A fire prevention foamed concrete insulation board. New Building Materials. 12(02), 69-72(2012).

2. ZHANG Xinqing, WU Xiaoxiang, WANG Zhanying, LI Guangqiu and XUE Liangliang, Recommendation of Class A Fire Exterior Insulation System. Construction Conserves Energy. 21(9), 57-59(2011).

3. SUN Shuli, CHEN Pu, YUAN Mingwu, Effect of bending stiffness in shear wall upon computational results of building structure. Chinese Journal of Computational Mechanics. 16(4), 421427(1999). 